\title{
ADMINISTRASI KELOMPOK WANITA TANI (KWT) DI KECAMATAN TOMOHON SELATAN KOTA TOMOHON
}

\author{
Margaretha Mariska Mamesah \\ Benu Olfie L.S \\ Jenny Baroleh
}

\begin{abstract}
This study aims to determine the administrative completeness of women farmer groups in Tomohon Selatan Subdistrict Tomohon City. This study was conducted from January to March 2017. The data used are primary data obtained from direct interviews with women farmer group organizations (Chief, Secretary, Treasurer) based on a prepared list of questions. The analysis used for the administrative variable of activity and financial administration that is each answer is related to the form of statement which is expressed with the words that is Good given Score: 3, Less Good is given Score: 2 and Not Good is given Score: 1. Result of research indicate that administration activity in Seruni and farmer group of Kemangi are complete while Flower is not complete. Seruni and Kemangi categorized good because $80 \%$ of books exist and complete filled and $20 \%$ was not complete, while group of farmer of Flower is categorized not good because only 60\% book filled with complete and $40 \%$ of the other administrative books are not exist. The Finance Administration of the three groups of women farmers is categorized as unfavorable because only 50\% of the books are available and are completed by the women farmer group.
\end{abstract}

Keywords: Administration, Women Farmer Group, Tomohon Selatan Subdistrict, Tomohon City.

\begin{abstract}
ABSTRAK
Penelitian ini bertujuan untuk mengetahui kelengkapan administrasi kelompok wanita tani di Kecamatan Tomohon Selatan, Kota Tomohon. Penelitian ini dilaksanakan pada bulan Januari sampai bulan Maret 2017. Data yang digunakan adalah data primer yang diperoleh dari wawancara langsung dengan organisasi kelompok wanita tani (Ketua, Sekretaris, Bendahara) berdasarkan daftar pertanyaan yang disiapkan. Analisis yang digunakan untuk variabel administrasi kegiatan dan administrasi keuangan yaitu setiap jawaban dihubungkan dengan bentuk pernyataan yang diungkapkan dengan kata-kata yaitu Baik diberikan Skor : 3, Kurang Baik diberikan Skor : 2 dan Tidak Baik diberikan Skor : 1. Hasil penelitian menunjukkan bahwa administrasi kegiatan pada kelompok wanita tani Seruni dan kelompok wanita tani Kemangi Lengkap sedangkan Kelompok tani Flower kurang lengkap. Kelompok wanita tani Seruni dan kelompok wanita tani Kemangi dikategorikan baik karena $80 \%$ buku ada dan diisi dengan lengkap dan $20 \%$ buku ada tetapi tidak diisi dengan lengkap, sedangkan kelompok wanita tani Flower dikategorikan kurang baik karena hanya $60 \%$ buku yang diisi dengan lengkap dan $40 \%$ buku administrasi yang lainnya tidak ada. Administrasi Keuangan pada ketiga kelompok wanita tani dikategorikan kurang baik karena hanya 50\% buku yang ada dan diisi dengan lengkap oleh pengurus kelompok wanita tani.
\end{abstract}

Kata Kunci: Atministrasi, Kelompok Wanita Tani, Kecamatan Tomohon Selatan, Kota Tomohon.

\section{PENDAHULUAN}

Latar Belakang
Pertanian merupakan kegiatan
pemanfaatan sumber daya hayati yang
dilakukan manusia untuk menghasilkan bahan
pangan, bahan baku industri, atau sumber

energi, serta untuk mengelola lingkungan hidupnya. Pertanian yang luas mencakup semua kegiatan yang melibatkan pemanfaatan makhluk hidup (termasuk tanaman, hewan, dan mikrobia) untuk kepentingan manusia. Dalam arti sempit, diartikan sebagai kegiatan pembudidayaan tanaman. Bagian terbesar 
penduduk dunia bermata pencaharian dalam bidang-bidang di lingkup pertanian (Nopriadi, 2013).

Petani sering dihadapkan dengan sosailisasi dan penyuluh pertanian, didalamnya penyuluh memenuhi administrasi. Administrasi yang di maksud adalah administrasi penyuluhan agar kegiatan sosialisasi berjalan dengaan lancar dan terstruktur. Kelembagaan penyuluhan pertanian merupakan salah satu wadah organisasi yang terdapat dalam Dinas Pertanian. Kelembagaan pertanian menyesuaikan dengan perubahan-perunahan yang ada. Organisasi digunakan sebagai tempat dimana orang berkumpul, bekerjasama secara rasional dan sistematis, terencana, terorganisasi, terpimpin dan terkendali, dalam memanfaatkan sumber daya (uang, material, mesin, metode, lingkungan), sarana-prasarana, data sebagainya yang digunakan secara efisien dan efektif untuk mencapai tujuan organisasi (Ode, 2014).

Administrasi sangat penting dalam suatu organisasi. Keberhasilan suatu organisasi dapat diukur dari administrasi. Dalam penyelenggaraan kerja yang dilakukan oleh orang-orang secara bersama-sama untuk mencapai tujuan tang ditetapkan dan juga administrasi yang menjalankan suatu kegiatan kelompok tani, dimana administrasi ini berupa buku daftar anggota, daftar tamu, keuangan, hadir rapat, dan lain-lain administrasi sangat diperlukan. Administrasi Pertanian sangat penting bagi masyarakat khususnya kelompok tani, dengan adanya sumber daya manusia merupakan salah satu faktor kunci dalam reformasi ekonomi, yaitu menciptakan sumber daya manusia yang berkualitas dan memiliki keterampilan serta berdaya saing tinggi dalam menghadapi persaingan global yang selama ini terabaikan.

Dalam perangkat administrasi dibedakan menjadi dua pokok yaitu : administrasi kegiatan dan administrasi keuangan. Dalam administrasi kegiatan, segala catatan dilakukan oleh kelompok berkaitan dengan kegiatan kelompok diluar urusan keuangan seperti buku induk anggota, buku tamu, buku notulen rapat, buku kegiatan kelompok, buku produktifitas dan hasil produksi, buku agenda surat masuk dan surat keluar, buku ekspedisi, buku kepemilikan sarana/prasarana anggota, buku luas lahan garapan, buku pengurus, buku daftar hadir, sedangkan administrasi keuangan, segala catatan yang khusus berkaitan dengan keuangan kelompok seperti buku kas, buku iuran anggota, buku tabungan anggota, buku inventaris, buku penjualan, buku pembelian (Kementrian Pertanian, 2014). Selain itu kelompok tani atau kelompok wanita tani yang sudah maju, diharapkan juga memiliki perangkat kelengkapan administrasi lainnya seperti sekretariat kelompok tani, papan nama kelompok tani, stempel kelompok tani, arsip surat masuk dan surat keluar, arsip dokumen berita acara pembentukan kelompok tani, arsip dokumen AD dan ART kelompok tani, arsip dokumen berita acara benah kelompok tani, rencana kerja kelompok atau Rencana Definitif Kelompok tani (RDK), Rencana Definitif Kebutuhan Kelompok tani (RDKK), Rencana Usaha Anggota (RUA), arsip dokumen biodata anggota kelompok tani, dokumen berupa papan data (monografi) kelompok tani, dan peta wilayah kelompok tani.

Kota Tomohon sebagian besar merupakan masyarakat petani. Menurut data BP4K Kota Tomohon memiliki 476 kelompok tani dan masing-masing kecamatan memiliki Kelompok Wanita Tani. Kecamatan Tomohon Selatan sendiri mempunyai 87 kelompok tani dan yang terdaftar di BP3K masing-masing kelurahan terdapat 1 orang PPL. Salah satunya yang terdapat Kelompok Wanita Tani yaitu Kecamatan Tomohon Selatan dengan Kelompok Wanita Tani Seruni di Kelurahan Lahendong, Kelompok Wanita Tani Kemangi di Kelurahan Lansot, dan Kelompok Wanita Tani Flower di Kelurahan Tumatangtang. Menjadi hal yang sangat menarik untuk diteliti bagaimana kelengkapan administrasi kegiatan maupun administrasi keuangan kelompok wanita tani di Kecamatan Tomohon Selatan yang diukur dari atau diwakili oleh tiga kelompok wanita tani diKecamatan Tomohon Selatan.

\section{Kelompok Tani}

Kelompok tani merupakan sekumpulan petani yang terkait secara non formal atas dasar keserasian, kondisi lingkungan, keakraban, kepentingan bersama dan saling mempercayai serta mempunyai pimpinan untuk mencapai tujuan (Kartasapoetra dalam Damima, 2001). 
Nuryanti dan Swastika (2011) menjelaskan bahwa secara umum, kelompok tani dibentuk untuk memecahkan permasalahan yang dihadapi petani yang tidak bisa diatasi secara individu, kelompok tani dapat dibentuk secara swadaya maupun atas dasar kepentingan kebijakan dari pemerintah melalui Dinas Pertanian.

\section{Kelompok Wanita Tani}

Kelompok Wanita Tani adalah kumpulan ibu-ibu istri petani atau para wanita yang mempunyai aktivitas dibidang pertanian yang tumbuh berdasarkan keakraban, keserasian, serta kesamaan kepentingan dalam memanfaatkan sumberdaya pertanian untuk bekerjasama meningkatkan produktivitas usahatani dan kesejahteraan anggotanya.

\section{Administrasi}

Administrasi adalah proses kegiatan dengan bantuan berbagai sumber untuk mencapai tujuan yang telah ditentukan sebelumnya. Pengertian administrasi secara sempit adalah berasal dari kata administratie (bahasa Belanda), yang meliputi kegiatan seperti catat mencatat, pembukuan ringan, surat- menyurat, ketik-mengetik, agenda dan lain-lain, yang bersifat teknis ketatausahaan (clerical work). Dengan demikian tata usaha adalah sebagian kecil kegiatan dari administrasi. Pengertian Administrasi secara sempit merupakan penyusunan dan juga pencatatan data, juga informasi secara sistematis yang dimaksudkan untuk menyediakan keterangan serta memudahkan memperolehnya kembali secara keseluruhan dan dalam hubungannya satu sama lain (Haryadi, 2009).

\section{Rumusan Masalah}

Berdasarkan latar belakang yang menjadi masalah dalam penelitian ini yaitu bagaimana kelengkapan administrasi kelompok wanita tani dikecamatan Tomohon Selatan Kota Tomohon?

\section{Tujuan Penelitian}

Penelitian ini bertujuan untuk mengetahui kelengkapan administrasi kelompok wanita tani di Kecamatan Tomohon Selatan Kota Tomohon.

\section{Manfaat Penelitian}

Penelitian ini diharapkan dapat bermanfaat bagi:

1. Kelompok Wanita Tani (Petani)

Menambahkan pemahaman kepada kelompok wanita tani tentang kelengkapan administrasi kegiatan dan administrasi keuangan agar lebih diperhatikan dan di lengkapi karena administrasi dalam kelompok tani sangat penting dalam kelangsungan organisasi kelompok wanita tani dan kemajuan kelompok wanita tani.

2. Pemerintah

Memberikan arahan kepada penyuluh dan kelompok wanita tani untuk dapat mengikuti setiap peraturan dan persyaratan yang diberikan pemerintah bagi para penyuluh dan kelompok wanita tani demi kemajuan pembangunan dalam bidang pertanian.

3. Peneliti

Selain untuk penyelesaian studi akhir, juga dapat menambah pengetahuan dalam kelengkapan administrasi pada kelompok wanita tani.

\section{METODOLOGI PENELITIAN}

\section{Waktu dan Lokasi Penelitian}

Penelitian ini berlangsung selama 3 (tiga) bulan yaitu mulai Bulan November 2016 sampai Januari 2017. Tempat Penelitian dilakukan di Kecamatan Tomohon Selatan Kota Tomohon.

\section{Metode Pengambilan Sampel}

Metode pengambilan sampel pada 3 (tiga) kelompok wanita tani yang ada di Kecamatan Tomohon Selatan Kota Tomohon dilakukan dengan cara sengaja yaitu pada Kelompok Wanita Tani Seruni di Kelurahan Lahendong, Kelompok Wanita Tani Flower di Kelurahan Tumatangtang, Kelompok Wanita Tani Kemangi di Kelurahan Lansot.

\section{Metode Pegambilan Data}

Metode yang digunakan dalam penelitian ini yaitu metode survey. Data yang digunakan adalah data primer yang diperoleh dari wawancara langsung dengan organisasi 
kelompok wanita tani (Ketua, Sekretaris, Bendahara) berdasarkan daftar pertanyaan yang disiapkan.

\section{Konsepsi Pengukuran Variabel}

Variabel di ukur dalam penelitian ini yakni :

1. Struktur organisasi kelompok tani (Ketua, Sekretaris, Bendahara).

2. Karakteristik kelompok tani

a. Nama kelompok tani

b. Tahun berdiri kelompok tani

c. Jumlah anggota kelompok tani

d. Kelengkapan administrasi kelompok tani di lihat dari 2 bagian pokok administrasi yaitu : Administrasi kegiatan dan Administrasi Keuangan.

e. Administrasi Kegiatan adalah segala catatan dilakukan oleh kelompok berkaitan dengan kegiatan kelompok seperti buku induk anggota, buku tamu, buku notulen rapat, buku kegiatan kelompok, buku produktivitas dan hasil produksi, buku agenda surat masuk dan surat keluar, buku ekspedisi, buku luas lahan garapan, buku pengurus, buku daftar hadir.

f. Administrasi Keuangan adalah segala catatan yang khusus berkaitan dengan keuangan kelompok seperti buku kas, buku iuran anggota, buku tabungan anggota, buku inventaris, buku penjualan, buku pembelian, buku kepemilikkan sarana/prasaran.

\section{Analisis Data}

Metode analisis data yang digunakan dalam penelitian ini adalah metode analisis deskriptif, dengan mendeskripsikan dari tabel penelitian, berdasarkan kriteria kelengkapan administrasi yakni :

1. Baik (3) = di ukur dengan melihat kelengkapan administrasi dalam kelompok tani (administrasi kegiatan dan administrasi keuangan (buku ada dan diisi dengan lengkap)).

2. Kurang Baik (2) = di lihat dari kelengkapan administrasi (administrasi kegiatan dan administrasi keuangan (buku ada dan tidak diisi dengan lengkap)).

3. Tidak Baik (1) = di ukur dengan melihatnnya kelengkapan administrasi (administrasi kegiatan dan administrasi keuangan (buku tidak ada)).

1) Administrasi Kegiatan

Dari semua elemen yang disusun 11 pertanyaan dengan total responden 3 kelompok tani. Setiap jawaban dihubungkan dengan bentuk pertanyaan yang diungkapkan dengan kata-kata berikut :

$$
\text { Baik Skor : } 3
$$

Kurang Baik Skor : 2

Tidak Baik Skor : 1

Dengan cara perhitungan Range masingmasing pertanyaan:

Nilai Tertinggi : $3 \times 11=33$

Nilai Terendah : $1 \times 11=11$

Jumlah Kategori $=3$

Range $=\frac{\text { Nilai Tertinggi }- \text { Nilai Terendah }}{\text { Jumlah Kategori }}$

Range $=\frac{33-11}{3}=7,33$

Jumlah skor ideal untuk setiap pertanyaan $($ Skor tertinggi $)=33$

Jumlah skor terendah $=11$

Range $=7,33$

Dengan intepretasi nilai :

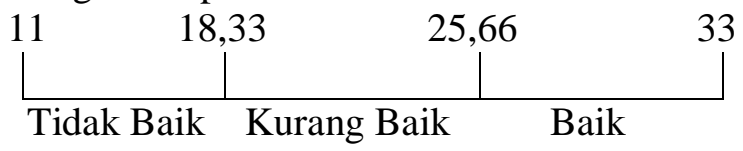

Gambar 1. Interpretasi Nilai pada Range Administrasi Kegiatan

Tabel 1. Interval dan Kriteria pada Administrasi Kegiatan

\begin{tabular}{cc}
\hline Interval & Kriteria \\
\hline $11-18,33$ & Tidak Baik \\
$18,34-25,66$ & Kurang Baik \\
$25,67-33$ & Baik \\
\hline
\end{tabular}

Keterangan

1. $11-18,33$ (Tidak Baik $)=$ Kelengkapan Administrasi tidak ada atau buku tidak ada

2. 18,34 - 25,66 (Kurang Baik) = Kelengkapan Administrasi ada tetapi tidak diisi dengan lengkap 
3. $25,34-33$ (Baik) = Kelengkapan Administrasi Lengkap

2) Administrasi Keuangan

Dari semua elemen yang ada di susun 6 pertanyaan dengan total responden 3 kelompok tani. Setiap jawaban dihubungkan dengan bentuk pertanyaan yang diungkapkan dengan kata-kata berikut:
Baik
Skor : 3
Kurang Baik
Skor : 2
Tidak Baik
Skor : 1

Dengan cara perhitungan Range masing-masing pertanyaan:

Nilai Tertinggi : $3 \times 6=18$

Nilai Terendah : $1 \times 6=6$

Jumlah Kategori $=3$

Range $=\frac{\text { Nilai Tertinggi }- \text { Nilai Terendah }}{\text { Jumlah Kategori }}$

Range $=\frac{18-6}{3}=4$

Jumlah Skor Ideal untuk setiap pertanyaan (skor tertinggi) $=18$

Jumlah skor terendah $=6$

Range $=4$

Dengan intepretasi nilai :

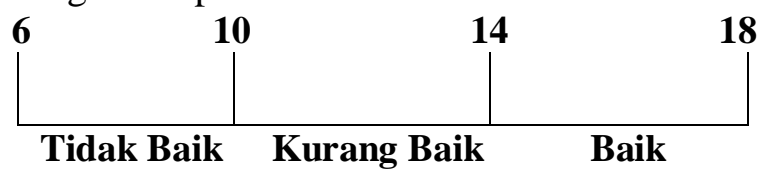

Gambar 2. Interpretasi Nilai pada Range Administrasi Keuangan

Tabel 2. Interval dan Kriteria pada Administrasi Keuangan

\begin{tabular}{cc}
\hline Interval & Kriteria \\
\hline $6-10$ & Tidak Baik \\
$11-14$ & Kurang Baik \\
$15-18$ & Baik \\
\hline
\end{tabular}

Keterangan

1. $6-10$ (Tidak Baik $)=$ Kelengkapan Administrasi tidak ada atau buku tidak ada

2. $11-14$ (Kurang Baik) = Kelengkapan Administrasi ada tetapi tidak diisi dengan lengkap

3. $15-18$ (Baik) = Kelengkapan Administrasi Lengkap

\section{HASIL DAN PEMBAHASAN}

\section{Deskripsi Lokasi Penelitian}

\section{Geografis}

Kota Tomohon merupakan salah satu daerah yang ada di Sulawesi Utara, dapat dicapai dengan menggunakan transportasi darat dari ibu kota Provinsi Sulawesi Utara, Manado $\pm 25 \mathrm{Km}$, jika dari bandara Internasional Sam Ratulangi $\pm 34 \mathrm{Km}$.

Sementara untuk kabupaten/kota yang berdekatan dengan Kota Tomohon adalah Kabupaten Minahasa Selatan (sebelah Barat) Kota Manado (sebelah Utara) Kabupaten Minahasa (sebelah Timur) dan Kabupaten Minahasa Tenggara (sebelah Selatan).

Kecamatan Tomohon Selatan merupakan bagian dari Kota Tomohon yang mempunyai batas wilayah sebagai berikut :

a. Sebelah Utara berbatasan dengan Kecamatan Tomohon Tengah

b. Sebelah Selatan berbatasan dengan Kecamatan Sonder (Kabupaten Minahasa)

c. Sebelah Barat berbatasan dengan Kecamatan Tomohon Barat

d. Sebelah Timur berbatasan dengan Kecamatan Tondano (Kabupaten Minahasa).

\section{Iklim}

a) Curah Hujan

Gambaran kondisi curah hujan rata-rata bulanan selama tahun 1993-2004 diamati oleh Stasiun Geofisika Tondano, memperlihatkan curah hujan maksimum pertama terjadi pada Bulan April dan maksimum kedua terjadi pada Bulan November sebesar $245 \mathrm{~mm}$. Sedangkan curah hujan terendah terjadi pada Bulan Agustus sebesar $98 \mathrm{~mm}$. Berdasarkan peta iklim Oldeman tipe iklim untuk lokasi Tomohon dan sekitarnya termasuk tipe iklim D1 (iklim tropis).

b) Suhu Udara

Suhu udara rata-rata bulanan dari bulan ke bulan sepanjang tahun relatif kecil variasinya. Suhu rata-rata bulanan mencapai maksimum sekitar Bulan Juli dan suhu ratarata bulanan terendah sekitar bulan Januari. Suhu rata-rata hanya berfluktuasi antara $22.02^{\circ} \mathrm{C}$ pada bulan Januari sampai $22.8^{\circ} \mathrm{C}$. 


\section{Karakteristik Kelompok Wanita Tani}

Kelompok tani pada dasarnya merupakan kelembagaan petani dipedesaan yang saling mengenal dengan akrab dan saling percaya antara anggota kelompok tani termasuk kelompok wanita tani, yang mempunyai pandangan dan kepentinagan serta tujuan yang sama dalam berusaha tani. Kerja sama yang dilakukan antara pengurus dengan anggota, anggota dengan penyuluh sangat berpengaruh bagi perkembangan usaha tani dalam kelompok tani atau dalam kelompok wanita tani. Tabel 3 menunjukkan karakteristik kelompok tani.

Tabel 3. Karakteristik Kelompok Wanita Tani Responden di Kecamatan Tomohon Selatan

\begin{tabular}{lllcc}
\hline No. & $\begin{array}{c}\text { Kelompok } \\
\text { Wanita } \\
\text { Tani }\end{array}$ & Alamat & $\begin{array}{c}\text { Tahun } \\
\text { Berdiri }\end{array}$ & $\begin{array}{c}\text { Jumlah } \\
\text { Anggota }\end{array}$ \\
\hline 1. & Seruni & Lahendong & 2006 & 19 \\
2. & Kemangi & Lansot & 2013 & 36 \\
3. & Flower & Tumatangtang & 2006 & 10 \\
\hline
\end{tabular}

Sumber : Diolah dari data primer 2017

\section{Karakteristik Responden}

\section{Umur Responden}

Tingkat Umur sangat mempengaruhi kemamouan seseorang dalam melakukan aktifitas ataupun konsep berpikir khususnya tiap anggota kelompok wanita tani. Anggota kelompok wanita tani yang memiliki umur muda tentunya memiliki kondisi fisik yang lebih kuat dan ingin untuk mencoba hal-hal yang baru, serta memeliki kemampuan daya pikir yang lebih kreatif. Selain itu anggota kelompok wanita tani yang berumur tua cenderung untuk menjaga kesehatannya. Dari data primer yang di peroleh usia responden kelompok wanita tani antara 32-60 tahun. Komposisi umur responden dalam penelitian disajikan pada Tabel 4.

Tabel 4. Menunjukkan bahwa jumlah responden dari 3 Kelompok Wanita Tani Seruni Kelurahan Lahendong, Kemangi Kelurahan Lansot, Flower Kelurahan Tumatangtang. Pada interval umur 30-40 tahun yaitu 2 orang pada kelompok wanita tani Seruni dan kelompok wanita tani Flower masing-masing 1 responden (33,33\%), sedangkan pada interval umur 41-50 tahun yaitu 4 orang pada kelompok wanita tani
Kemangi dan kelompok wanita tani Folwer yang masing-masing 2 responden $(66,67 \%)$. Selanjutnya berada pada interval umur 51-60 tahun kelompok wanita tani Seruni terdapat 2 responden $(66,67 \%)$ dan kelompok wanita tani Kemangi terdapat 1 responden $(33,33 \%)$.

Tabel 4. Jumlah Responden Menurut Tingkat Umur

\begin{tabular}{ccccccc}
\hline \multirow{2}{*}{$\begin{array}{c}\text { Umur } \\
\text { (Tahun) }\end{array}$} & \multicolumn{3}{c}{ Jumlah Responden } & \multicolumn{3}{c}{ Persentase (\%) } \\
\cline { 2 - 7 } & Seruni & Kemangi & Flower & Seruni & Kemangi & Flower \\
\hline $30-40$ & 1 & - & 1 & 33,33 & - & 33,33 \\
$41-50$ & - & 2 & 2 & - & 66,67 & 66,67 \\
$51-60$ & 2 & 1 & - & 66,67 & 33,33 & - \\
\hline Jumlah & 3 & 3 & 3 & 100 & 100 & 100 \\
\hline Sulmyyyyyy
\end{tabular}

Sumber : Diolah dari data Primer 2017

\section{Pendidikan Responden}

Tingkah laku individu atau seseorang sangat dipengaruhi oleh pendidikan yang telah dicapai. Begitu juga pada anggota kelompok wanita tani, tingkat pendidikan dan pengalaman sangat mempengaruhi cara berpikir. Tabel 5 menunkukkan tingkat pendidikan responden.

Tabel 5. Jumlah Responden Menurut Tingkat Pendidikan

\begin{tabular}{|c|c|c|c|c|c|c|}
\hline \multirow{2}{*}{$\begin{array}{c}\text { Tingkat } \\
\text { Pendidikan }\end{array}$} & \multicolumn{3}{|c|}{ Jumlah Responden } & \multicolumn{3}{|c|}{ Persentase (\%) } \\
\hline & $\overline{\text { Seruni }}$ & Kemangi & Flower & Seruni & Kemangi & Flower \\
\hline SMA & 3 & 2 & 2 & 100 & 66,67 & 66,67 \\
\hline S1 & - & 1 & 1 & - & 33,33 & 33,33 \\
\hline Jumlah & 3 & 3 & 3 & 100 & 100 & 100 \\
\hline
\end{tabular}

Sumber : Diolah dari data Primer 2017

Tabel 5, menunjukkan tingkat pendidikan pada kelompok wanita tani Seruni Kelurahan Lahendong, dengan responden terbanyak yaitu SMA ada 3 responden (100\%), begitu juga dengan kelompok wanita tani Kemangi dan kelompok wanita tani Flower terdapat 4 responden masing-masing 2 responden $(66,67 \%)$ yang ada pada tingkat pendidikan SMA. Sedangkan kelompok wanita tani yang mempunyai tingkat $\mathrm{S} 1$ terdapat 2 responden yaitu pada kelompok wanita tani Kemangi dan kelompok wanita Flower yang masing-masing terdapat 1 responden $(33,33 \%)$. 


\section{Pengalaman Berusahatani}

Tingkah laku individu terhadap seseorang sangat dipengaruhi oleh lamanya mereka berusahatani, karena mempengaruhi cara berpikir seseorang lebih lama kita bekerja lebih banyak wawasan seseorang anggota dalam setiap kegiatan, aktivitas dan lebih mengetahui apa yang belum diketahui oleh anggota yang lain. Tabel 6 menunjukkan jumlah responden menurut pengalaman bekerja.

Tabel 6. Jumlah Responden Menurut Pengalaman Berusahatani

\begin{tabular}{lccc}
\hline No. & $\begin{array}{c}\text { Pengalaman } \\
\text { Berusaha Tani } \\
\text { (Tahun) }\end{array}$ & $\begin{array}{c}\text { Jumlah } \\
\text { Responden }\end{array}$ & $\begin{array}{c}\text { Persentase } \\
(\%)\end{array}$ \\
\hline 1. & 8 & 1 & 11,11 \\
2. & 9 & 1 & 11,11 \\
3. & 10 & 6 & 66,67 \\
4. & 11 & 1 & 11,11 \\
\hline Jumlah & & 9 & 100 \\
\hline
\end{tabular}

Sumber : Diolah dari data Primer 2017

Tabel 6 menunjukkan tingkat lamanya pengalaman bekerja usahatani setiap responden menjadi anggota kelompok wanita tani terbanyak yaitu 10 tahun sebanyak 6 responden $(66,67 \%), 8$ tahun 1 responden (11,11\%), 9 tahun 1 responden $(11,11 \%)$, dan 11 tahun ada 1 responden $(11,11 \%)$.

\section{Administrasi Kegiatan Kelompok Wanita \\ Tani Seruni Kelurahan Lahendong Kecamatan Tomohon Selatan}

Administrasi kegiatan merupakan penyusunan dan pencatatan data serta informasi, dengan tujuan untuk menyediakan keterangan. Administrasi Kegiatan begitu penting bagi setiap organisasi kelompok tani termasuk dalam kelompok wanita tani untuk menunjang kemajuan kelompok wanita tani dimana semua kekurangan dan kelebihan dalam kelompok bisa diketahui melalui pembukuan administrasi kegiatan. Kelompok Wanita Tani Seruni adalah salah satu kelompok wanita tani yang berada jauh dengan Balai Penyuluhan Pertanian Perikanan dan Kehutanan (BP3K) di Kecamatan Tomohon Selatan, kelompok wanita tani Seruni adalah kelompok wanita tani yang masih aktif dengan jumlah anggota 19 orang, berdiri mulai tahun 2006 sampai dengan sekarang. Tanaman yang paling dominan di kelompok wanita tani adalah Jagung dengan luas lahan 10 ha. Kelompok wanita tani ini juga selalu mengadakan pertemuan setiap minggu pada hari selasa jam 19.00 Wita. Peran aktif pengurus dan anggota kelompok sangat berpengaruh dalam kelangsungan kegiatan kelompok tani. Pengurus kelompok wanita tani Seruni sering mengikuti pelatihan yang dilaksanakan oleh Dinas Pertanian sehingga lewat pelatihan yang diikuti oleh pengurus dapat diterapkan dan dipelajari oleh setiap anggota kelompok wanita tani, dan sekarang kelompok wanita tani ini berada dalam kelas kelompok Madya meskipun ada beberapa buku yang belum lengkap, dan dibuat oleh kelompok wanita tani. Administrasi kegiatan kelompok wanita tani Seruni di Kelurahan Lahendong dapat dilihat pada Tabel 7.

\begin{tabular}{|c|c|c|c|}
\hline & $\begin{array}{l}\text { 7. Administrasi } \\
\text { Wanita Tani } \\
\text { Lahendong }\end{array}$ & $\begin{array}{c}\text { Kegiatan } \\
\text { Seruni }\end{array}$ & $\begin{array}{l}\text { Kelompok } \\
\text { Kelurahan }\end{array}$ \\
\hline$\overline{\text { No. }}$ & Admistrasi Kegiatan & Skor & Keterangan \\
\hline 1. & Buku Induk Anggota & 3 & Baik \\
\hline 2. & Buku Tamu & 3 & Baik \\
\hline 3. & Buku Notulen Rapat & 3 & Baik \\
\hline 4. & Buku Kegiatan Kelompok & 3 & Baik \\
\hline 5. & $\begin{array}{l}\text { Buku Produktifitas dan Hasil } \\
\text { Produksi }\end{array}$ & 1 & Tidak Baik \\
\hline 6. & $\begin{array}{l}\text { Buku Agenda Surat Masuk dan } \\
\text { Surat Keluar }\end{array}$ & 3 & Baik \\
\hline 7. & Buku Ekspedisi & 2 & Kurang Baik \\
\hline 8. & $\begin{array}{l}\text { Buku Kepemilikan Sarana / } \\
\text { Prasarana }\end{array}$ & 1 & Tidak Baik \\
\hline 9. & Buku Luas Garapan & 1 & Tidak Baik \\
\hline 10. & Buku Pengurusan & 3 & Baik \\
\hline 11. & Buku Daftar Hadir & 3 & Baik \\
\hline
\end{tabular}

Sumber : Diolah dari data Primer 2017

Untuk mengetahui kelengkapan administrasi kegiatan dikelompok wanita tani Seruni, maka perlu dihitung jumlah keseluruhan skor pada setiap kriterium. Pada penelitian ini jumlah skor ideal (tertinggi), yaitu 33 dan jumlah skor terendah yaitu 11. Berdasarkan data yang dihimpun dari 11 indikator pertanyaan yang diajukan kepada 3 responden, maka diperoleh total skor 26 dengan kriteria baik. Letak skor ditentukan dalam jangkauan sebagai berikut :

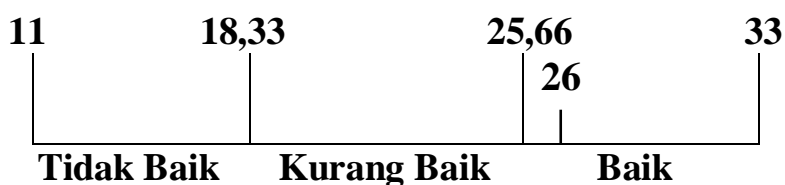

Gambar 3. Interpretasi Nilai pada Range Administrasi Kegiatan Kelompok Wanita Tani Seruni 


\section{Administrasi Keungan Kelompok Wanita \\ Tani Seruni Kelurahan Lahendong Kecamatan Tomohon Selatan}

Tabel 8 menunjukkan administrasi keuangan kelompok wanita tani Seuni Kelurahan Seruni Kecamatan Tomohon Selatan Kota Tomohon.

Tabel 8. Administrasi Keuangan Kelompok Wanita Tani Seruni di Kelurahan Lahendong

\begin{tabular}{llcc}
\hline No. & \multicolumn{1}{c}{$\begin{array}{c}\text { Administrasi } \\
\text { Keuangan }\end{array}$} & Skor & Keterangan \\
\hline 1. & Buku Kas & 2 & Kurang Baik \\
2. & Buku Iuran Anggota & 3 & Baik \\
3. & Buku Tabungan & 2 & Kurang Baik \\
4. & Bnggota & 1 & Tidak Baik \\
5. & Buku Penjualan & 1 & Tidak Baik \\
6. & Buku Pembelian & 1 & Tidak Baik \\
\hline & Jumlah & 10 & \\
\hline
\end{tabular}

Sumber : Diolah dari data Primer 2017

Untuk mengetahui kelengkapan administrasi keuangan pada kelompok wanita tani Seruni, maka perlu dihitung jumlah keseluruhan skor pada setiap kriterium. Pada penelitian ini jumlah skor ideal (tertinggi) yaitu, 18 dan jumlah skor terendah 6 . Berdasarkan data yang dihimpun dari sebanyak 6 indikator pertanyaan yang diajukan kepada 3 responden, maka diperoleh total skor 11 dengan kriteria kurang baik. Letak skor ditentukan dalam jangkauan sebagai berikut :

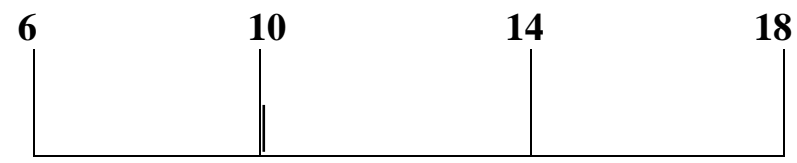

Tidak Baik Kurang Baik Baik

Gambar 4. Interpretasi Nilai pada Range Administrasi Keuangan Kelompok Wanita Tani Seruni

Administrasi Kegiatan Kelompok Wanita Tani Kemangi Kelurahan Lansot Kecamatan Tomohon Selatan

Kelompok Wanita Tani Kemangi Kelurahan Lansot berada dekat dengan kantor Balai Penyuluhan Pertanian Perikanan dan Kehutanan (BP3K) di Kecamatan Tomohon
Selatan. Kelompok wanita tani Kemangi adalah kelompok wanita tani yang masih aktif dan berdiri pada tahun 2013 dengan jumlah anggota 36 orang, dan pertemuan kelompok wanita tani dilaksanakan seminggu sekali pada hari selasa, dan tiap 3 (tiga) bulan kelompok wanita tani kemangi ini diperiksa dan dikunjungi oleh dinas pertanian setempat sehingga pada tahun 2013 kelompok wanita tani ini mendapatkan bantuan dan mendapat pembinaan dari PPL. Pada musim panas tahun 2016 kelompok wanita tani kemangi sempat terhenti karena mengalami kekeringan air namum menurut sekretaris kelompok wanita tani kemangi kelompok wanita tani ini akan melanjutkan kembali dan akan memperbaiki serta akan meningkatkan daya dukung lahan sehingga dapat menjadi lahan usahatani yang lebih produktif. Peran aktif pengurus dan anggota kelompok sangat berpengaruh dalam kelangsungan kegiatan kelompok tani. Pengurus kelompok wanita tani Kemangi juga sering mengikuti pelatihan dan sosialisasi yang dilaksanakan oleh Dinas Pertanian sehingga lewat pelatihan yang diikuti oleh pengurus dapat diterapkan dan dipelajari oleh setiap anggota kelompok wanita tani, dan sekarang kelompok wanita tani ini berada dalam kelas kelompok Madya. Tanaman yang paling dominan di kelompok wanita tani ini adalah tanaman dapur hidup seperti kemangi, tomat, jahe, cabai rawit yang ada dipekarangan rumah setiap anggota kelompok wanita tani selain itu juga kelompok wanita tani memiliki kebun bersama dengan luas lahan 6 ha dengan menanam jagung, singkong, dan lain-lain. Hasil usaha tani kelompok wanita tani sebagian dijual dan hasil penjualan tersebut dimasukkan kedalam kas kelompok wanita tani guna untuk membeli pupuk dan sebagian dari hasil tanaman digunakan oleh anggota kelompok wanita tani sendiri. Tabel 9 menunjukkan kelengkapan administrasi kegiatan kelompok wanita tani Kemangi Kelurahan Lansot Kecamatan Tomohon Selatan. 
Tabel 9. Administrasi Kegiatan Kelompok Wanita Tani Kemangi Kelurahan Lansot

\begin{tabular}{|c|c|c|c|}
\hline No. & Admistrasi Kegiatan & Skor & Keterangan \\
\hline 1. & Buku Induk Anggota & 3 & Baik \\
\hline 2. & Buku Tamu & 3 & Baik \\
\hline 3. & Buku Notulen Rapat & 3 & Baik \\
\hline 4. & Buku Kegiatan Kelompok & 3 & Baik \\
\hline 5. & $\begin{array}{l}\text { Buku Produktifitas dan Hasil } \\
\text { Produksi }\end{array}$ & 2 & Kurang Baik \\
\hline 6. & $\begin{array}{l}\text { Buku Agenda Surat Masuk dan } \\
\text { Surat Keluar }\end{array}$ & 1 & Tidak Baik \\
\hline 7. & Buku Ekspedisi & 1 & Tidak Baik \\
\hline 8. & $\begin{array}{l}\text { Buku Kepemilikan Sarana / } \\
\text { Prasarana }\end{array}$ & 3 & Baik \\
\hline 9. & Buku Luas Garapan & 1 & Tidak Baik \\
\hline 10. & Buku Pengurusan & 3 & Baik \\
\hline \multirow[t]{2}{*}{11.} & Buku Daftar Hadir & 3 & Baik \\
\hline & Jumlah & 26 & \\
\hline
\end{tabular}

Sumber : Diolah dari data Primer 2017

Untuk mengetahui kelengkapan administrasi kegiatan dikelompok wanita tani Kemangi, maka perlu dihitung jumlah keseluruhan skor pada setiap kriterium. Pada penelitian ini jumlah skor ideal (tertinggi), yaitu 33 dan jumlah skor terendah yaitu 11 . Berdasarkan data yang dihimpun dari 11 indikator pertanyaan yang diajukan kepada 3 responden, maka diperoleh total skor 26 dengan kriteria baik. Letak skor ditentukan dalam jangkauan sebagai berikut :

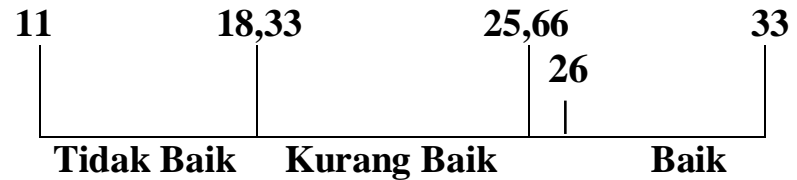

Gambar 5. Interpretasi Nilai pada Administrasi Kegiatan Kelompok Wanita Tani Kemangi

\section{Administrasi Keuangan Kelompok Wanita Tani Kemangi Kelurahan Lansot Kecamatan Tomohon Selatan}

Berikut ini adalah hasil penelitian tentang administrasi keuangankelompok wanita tani Kemangi. Tabel 10 menunjukkan administrasi keuangan kelompok wanita tani Kemangi Kelurahan Lansot Kecamatan Tomohon Selatan.
Tabel 10. Administrasi Keuangan Kelompok Wanita Tani Kemangi Kelurahan Lansot

\begin{tabular}{lllc}
\hline No. & \multicolumn{1}{c}{$\begin{array}{c}\text { Administrasi } \\
\text { Keuangan }\end{array}$} & Skor & Keterangan \\
\hline 1. & Buku Kas & 3 & Baik \\
2. & Buku Iuran Anggota & 1 & Tidak Baik \\
3. & Buku Tabungan & 3 & Baik \\
4. & Bnggota & 3 & Baik \\
5. & Buku Penjualan & 1 & Tidak Baik \\
6. & Buku Pembelian & 1 & Tidak Baik \\
\hline & Jumlah & 12 & \\
\hline
\end{tabular}

Sumber : Diolah dari data Primer 2017

Untuk mengetahui kelengkapan administrasi keuangan pada kelompok wanita tani Kemangi, maka perlu dihitung jumlah keseluruhan skor pada setiap kriterium. Pada penelitian ini jumlah skor ideal (tertinggi) yaitu, 18 dan jumlah skor terendah 6. Berdasarkan data yang dihimpun dari sebanyak 6 indikator pertanyaan yang diajukan kepada 3 responden, maka diperoleh total skor 12 dengan kriteria tidak baik. Letak skor ditentukan dalam jangkauan sebagai berikut:

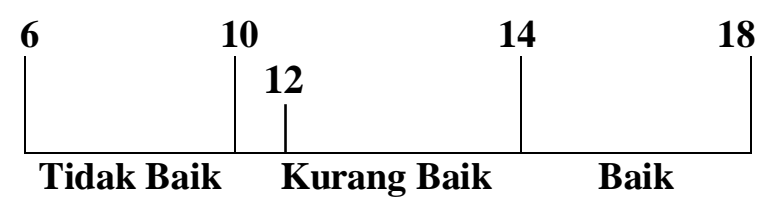

Gambar 6. Interpretasi Nilai pada Range Administrasi Keuangan Kelompok Wanita Tani Kemangi

\section{Administrasi Kegiatan Kelompok Wanita \\ Tani Flower Kelurahan Tumatangtang Kecamatan Tomohon Selatan}

Kelompok wanita tani Flower Kelurahan Tumatangtang merupakan kelompok wanita tani yang dulunya adalah satu dengan kelompok wanita tani flower yang sekarang ada di Kelurahan Tumatangtang 1 namun karena adanya pemekaran wilayah diKelurahan Tumatangtang sehinng terbagi menjadi 2 wilayah yaitu Kelurahan Tumatangtang dan Kelurahan Tumatangtang 1. Kelompok wanita tani Flower masih tetap memakai nama kelompok wanita tani Flower walaupun sudah terpisah dari kelompok yang sebelumnya. Kelompok wanita tani Flower berada dekat dengan Balai Penyuluhan Pertanian Perikanan 
dan Kehutanan (BP3K) di Kecamatan Tomohon Selatan. Kelompok wanita tani ini adalah kelompok yang masih aktif dengan anggota 10 orang, berdiri mulai tahun 2006 sampai sekarang. Kelompok wanita tani flower juga aktif dalam mengikuti pelatihan dan sosialisasi yang dilaksanakan oleh dinas pertanian kota Tomohon guna untuk meningkatkan dan memperbaiki usahatani yang lebih produktif, sehingga dapat mensejahterakan kelompok wanita tani itu sendiri dan dari kelas pemula naik ke kelas lanjut.

Kelompok ini bergerak dibidang usahatani buah-buahan dan sayuran dengan memanfaatkan pekarangan yang ada karena tanaman dipekarangan yang menjadi pokok dalam kelompok wanita tani flower sendiri, selain itu juga kelompok wanita tani ini memiliki kebun bersama dengan luas lahan 7 ha untuk menanam jagung. Kelompok ini juga sering mendapat bantuan dari Badan Ketahanan Pangan Kota Tomohon. Pertemuan diadakan setiap minggu. Kelompok wanita tani flower juga setiap minggu mendapat kunjungan dan pembinaan dari BP3K melalui PPL yang ada. Tabel 11 menunjukkan kelengkapan administrasi kegiatan dari kelompok wanita tani Flower Kelurahan Tumatangtang Kecamatan Tomohon Selatan.

Tabel 11. Administrasi Kegiatan Kelompok Wanita Tani Flower Kelurahan Tumatangtang

\begin{tabular}{|c|c|c|c|}
\hline$\overline{\text { No. }}$ & Admistrasi Kegiatan & Skor & Keterangan \\
\hline 1. & Buku Induk Anggota & 1 & Tidak Baik \\
\hline 2. & Buku Tamu & 3 & Baik \\
\hline 3. & Buku Notulen Rapat & 3 & Baik \\
\hline 4. & Buku Kegiatan Kelompok & 3 & Baik \\
\hline 5. & $\begin{array}{l}\text { Buku Produktifitas dan Hasil } \\
\text { Produksi }\end{array}$ & 1 & Tidak Baik \\
\hline 6. & $\begin{array}{l}\text { Buku Agenda Surat Masuk dan } \\
\text { Surat Keluar }\end{array}$ & 1 & Tidak Baik \\
\hline 7. & Buku Ekspedisi & 1 & Tidak Baik \\
\hline 8. & $\begin{array}{l}\text { Buku Kepemilikan Sarana / } \\
\text { Prasarana }\end{array}$ & 3 & Baik \\
\hline 9. & Buku Luas Garapan & 1 & Tidak Baik \\
\hline 10. & Buku Pengurusan & 3 & Baik \\
\hline 11. & Buku Daftar Hadir & 3 & Baik \\
\hline & Jumlah & 23 & \\
\hline
\end{tabular}

Sumber : Diolah dari data Primer 2017

Untuk mengetahui kelengkapan administrasi kegiatan dikelompok wanita tani
Kemangi, maka perlu dihitung jumlah keseluruhan skor pada setiap kriterium. Pada penelitian ini jumlah skor ideal (tertinggi), yaitu 33 dan jumlah skor terendah yaitu 11 . Berdasarkan data yang dihimpun dari 11 indikator pertanyaan yang diajukan kepada 3 responden, maka diperoleh total skor 23 dengan kriteria kurang baik. Letak skor ditentukan dalam jangkauan sebagai berikut :

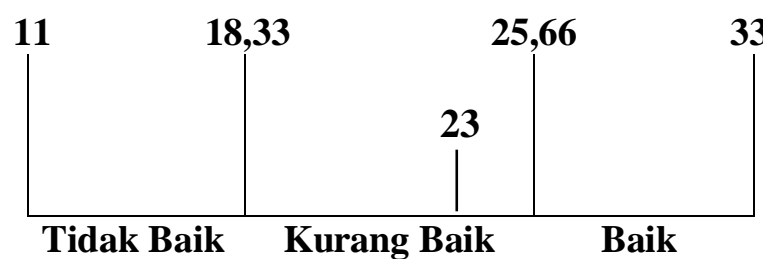

Gambar 7. Interpretasi Nilai pada Range Administrasi Kegiatan Kelompok Wanita Tani Flower

\section{Administrasi Keuangan Kelompok Wanita Tani Flower Kelurahan Tumatangtang Kecamatan Tomohon Selatan}

Berikut ini adalah hasil penelitian tentang administrasi keuangankelompok wanita tani Flower. Tabel 12 menunjukkan administrasi keuangan kelompok wanita tani Flower Kelurahan Tumatangtang Kecamatan Tomohon Selatan.

Tabel 12. Administrasi Keuangan Kelompok Wanita Tani Flower Kelurahan Tumatangtang

\begin{tabular}{|c|c|c|c|}
\hline No. & $\begin{array}{l}\text { Administrasi } \\
\text { Keuangan }\end{array}$ & Skor & Keterangan \\
\hline 1. & Buku Kas & 3 & Baik \\
\hline 2. & $\begin{array}{l}\text { Buku Iuran } \\
\text { Anggota }\end{array}$ & 3 & Baik \\
\hline 3. & $\begin{array}{l}\text { Buku Tabungan } \\
\text { Anggota }\end{array}$ & 3 & Baik \\
\hline 4. & Buku Investaris & 2 & Kurang Baik \\
\hline 5. & Buku Penjualan & 1 & Tidak Baik \\
\hline \multirow[t]{2}{*}{6.} & Buku Pembelian & 1 & Tidak Baik \\
\hline & Jumlah & 13 & \\
\hline
\end{tabular}

Sumber : Diolah dari data Primer 2017

Untuk mengetahui kelengkapan administrasi keuangan pada kelompok wanita tani Seruni, maka perlu dihitung jumlah keseluruhan skor pada setiap kriterium. Pada penelitian ini jumlah skor ideal (tertinggi) yaitu, 18 dan jumlah skor terendah 6. Berdasarkan data yang dihimpun 
dari sebanyak 6 indikator pertanyaan yang diajukan kepada 3 responden, maka diperoleh total skor 13 dengan kriteria kurang baik. Letak skor ditentukan dalam jangkauan sebagai berikut :

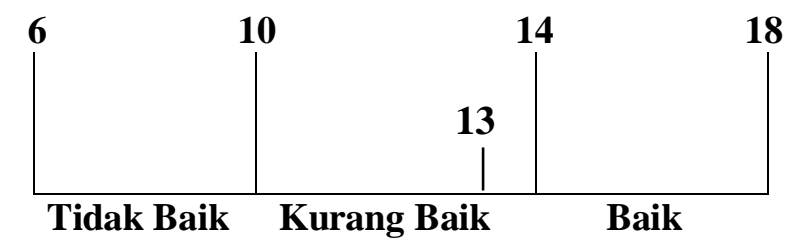

Gambar 8. Interpretasi Nilai pada Range Administrasi Keuangan Kelompok Wanita Tani Flower

\section{Rekapitulasi Administrasi Kelompok Wanita Tani di Kecamatan Tomohon Selatan Kota Tomohon}

Dari hasil rekapitukasi data administrasi kelompok wanita tani di Kecamatan Tomohon Selatan Kota Tomohon didapati total administrasi kegiatan 75 dengan hasil rata-rata $25 \%$ dan termasuk dalam kategori kurang baik. Sedangkan administrasi keuangan mendapatkan hasil total keseluruhan yaitu 35 dengan nilai rata-rata $11,67 \%$ dan termasuk dikategori kurang baik.

Tabel 13. Rekapitulasi Administrasi Kelompok Wanita Tani

\begin{tabular}{llcc}
\hline No & $\begin{array}{c}\text { Kelompok } \\
\text { Wanita } \\
\text { Tani }\end{array}$ & $\begin{array}{c}\text { Administrasi } \\
\text { Kegiatan } \\
\text { (Jumlah Skor) }\end{array}$ & $\begin{array}{c}\text { Administrasi } \\
\text { Keuangan } \\
\text { (Jumlah Skor) }\end{array}$ \\
\hline 1 & Seruni & 26 & 10 \\
2 & Kemangi & 26 & 12 \\
3 & Flower & 23 & 13 \\
& Total & 75 & 35 \\
& Rata-rata & $25 \%$ & $11,67 \%$ \\
\hline
\end{tabular}

Administrasi Kegiatan Kelompok Wanita Tani

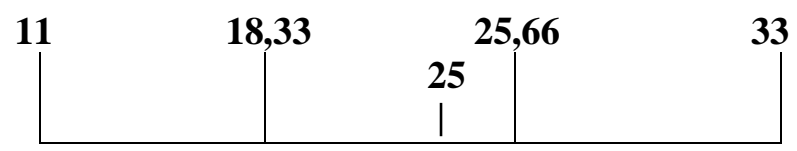

$\begin{array}{lll}\text { Tidak Baik } & \text { Kurang Baik } & \text { Baik }\end{array}$

Gambar 9. Interpretasi Nilai pada Range Administrasi Kegiatan Kelompok Wanita Tani di Kecamatan Tomohon Selatan
Administrasi Keuangan Kelompok Wanita Tani

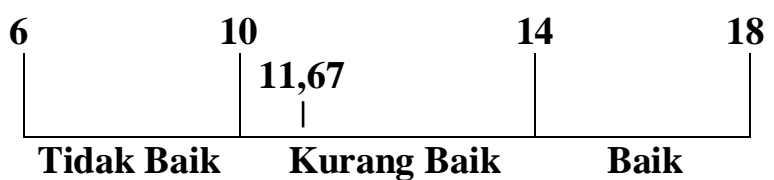

Gambar 10. Interpretasi Nilai pada Range Administrasi Kegiatan Kelompok Wanita Tani di Kecamatan Tomohon Selatan

\section{KESIMPULAN DAN SARAN}

\section{Kesimpulan}

Dari hasil penelitian pada tiga kelompok wanita tani ini menunjukkan bahwa :

1. Administrasi Kegiatan pada kelompok wanita tani Seruni dan kelompok wanita tani Kemangi dikategorikan baik karena $80 \%$ buku ada dan diisi dengan lengakap dan $20 \%$ buku ada tetapi tidak diisi dengan lengkap, sedangkan kelompok wanita tani Flower dikategorikan kurang baik karena hanya $60 \%$ buku yang diisi dengan lengkap dan $40 \%$ buku administrasi yang lainnya tidak ada.

2. Administrasi Keuangan pada ketiga kelompok wanita tani dikategorikan kurang baik karena hanya $50 \%$ buku yang ada dan diisi dengan lengkap oleh pengurus kelompok wanita tani.

\section{Saran}

Berdasarkan dari hasil penelitian maka disarankan Untuk Kelompok Wanita Tani yaitu:

1) Kelompok Wanita Tani Seruni

Meskipun kelengkapan administrasi kegiatan dikatakan baik dan administrasi keuangan dalam kriteria kurang baik, masih ada beberapa buku yang harus di lengkapi agar supaya dalam suatu organisasi kelompok wanita tani bisa berjalan dengtan baik.

2) Kelompok Wanita Tani Kemangi

Kelengkapan administrasi dalam kelompok wanita tani Kemangi sudah baik tetapi pengurus harus lebih memperhatikan lagi buku - buku yang belum dibuat oleh kelompok yaitu (buku agenda surat masuk dan surat keluar, buku ekspedisi, dan buku luas 
lahan garapan, buku iuran anggota, buku penjualan, dan buku pembelian).

3) Kelompok Wanita Tani Flower

Kelengkapan administrasi kelompok wanita tani Flower harus lebih diperhatikan oleh pengurus dan sebaiknya penyuluh harus lebih memperhatikan dan bersosialisasi dalam kelompok wanita tani dalam kelengkapan administrasi yang ada.

\section{DAFTAR PUSTAKA}

Balai Penyuluhan Pertanian Perikanan dan Kehutanan, 2016. Kecamatan Tomohon Selatan. Tomohon.

Damima, V., 2001. Dinamika Kelompok Tani Padi Sawah di Kecamatan Tondano Kabupaten Minahasa (Studi Kasus Terhadap Kelompok Tani di Desa Tataaran 1). Skripsi Fakultas Pertanian Universitas Sam Ratulangi. Manado.

Djamali, A R. 2000. Usahatani.: Pennerbit CV. Serajaya. Jakarta

Departemen Pertanian. 2007. Pedoman Pembinaan Kelembagaan Petani. http://www.deptan.go.id/bpsdm/peraturan /permentan\%20273-2007\%20

Lampiran\%201.PDF. (Diakses pada tanggal 16 Juli 2016).

Haryadi H. 2009. Administrasi Perkantoran Untuk Manajer dan Staf. Jakarta: Transmedia Pustaka.

Hermanto, 2007. Rancanagan Kelembagaan Tani dalam Implementasi Prima Tani diSumatera Selatan. Jurnal Analisis Kebijakan Pertanian.

Kementrian Pertanian, 2014. http://cybex.pertanian.go.id/materipenyul uhan (diakses pada tanggal 16 juli 2016).

Nopriadi, 2013. Ahli Fungsi Lahan Pertanian Menjadi Tempat Pemukiman DiKelurahan Jati Hilir Kecamatan
Pariman Tengah Kota, Jurnal Pendidikan Geografi, Vol 2, No 1.

Nuryanti dan Swatika. 2011. Peran Kelompok Tani dalam Penerapan Teknologi Pertanian.

Ode. Jurnal Ilmu Pertanian Indonesia Vol 19, No 1 (2014) Publisher: Iinstitut Pertanian Bogor.

Oudejans Jan, H.M, 2006. Perkembangan Pertanian Di Indonesia. UGM Press, Yogyakarta

Rahim. 2007. Ekonomi Pertanian. Penebar Swadaya,. Sinar Tani. Jakarta.

Rivai, Bahtiar. 1980. Ilmu Usahatani. Erlangga: Jakarta.

Shinta, A. 2011. Ilmu Usaha Tani. UB Press. Malang.

Suratiyah. 2006. Ilmu Usahatani. Penebar Swadaya. Jakarta.

Suswono, 2013. Pedoman Pembinaan Kelompok Tani dan Gabungan Kelompok Tani. Kementrian Pertanian. Jakarta.

Suwandi, Achmad. 2006. Administrasi Penyuluhan Pertanian. Universitas Terbuka. Jakarta.

Virginia, M.R. 2016. Administrasi Penyuluhan Pertanian Pada Kelompok Tani di Kecamatan Tabukan Utara KabupatenKepulauan Sangihe. Skripsi Fakultas Pertanian. Universitas Sam Ratulangi. Manado. 